\title{
EVOLUTION OF NORTH ATLANTIC WATER MASSES INFERRED FROM LABRADOR SEA SALINITY SERIES
}

BY IGOR YASHAYAEV

AND ALLYN CLARKE

\section{ABSTRACT}

The Labrador Sea is the coldest and freshest basin of the North Atlantic. Winter cooling in this sea produces Labrador Sea Water. This intermediate water plays an important role in the exchange of heat, freshwater, and other substances between the atmosphere and the abyssal ocean, affecting the water masses, circulation, and, ultimately, climate of the subpolar North Atlantic basins. The subpolar gyre of the North Atlantic has exhibited large changes in temperature, salinity, and volume over the past six decades, largely in response to changing winter conditions over the Labrador Sea. The signature of these changes can be seen in the lower limb of the Meridional Overturning Circulation down into the North Atlantic tropics.

\section{INTRODUCTION}

The subpolar sector of the North Atlantic Ocean is the region where the warm, saline upper-layer waters from the low (tropical and subtropical) latitudes meet the cold, less-saline outflows from the high (polar) latitudes and interact to mix and exchange their properties. It is also the region in which the major intermediate and deep water masses of the North Atlantic are created, modified, and joined together to form the lower limb of the "ocean conveyor belt."

The global ocean conveyor, by transforming poleward flows of warm saline upper waters to deep return flows of cold, less-saline waters, makes a significant contribution to the global distribution of heat, freshwater, and a variety of other substances carried by seawater (e.g., salts, nutrients, gases, pollutants). Although the salt content of the world ocean is approximately conserved, its local or regional signatures are affected by planetary freshwater and salt fluxes. Because the net poleward atmospheric moisture flux is largely compensated by the net oceanic freshwater transport, any sustained change in regional salinity would likely reveal an important tendency in the large-scale redistribution of freshwater and sea salt that would provide insight for understanding and predicting possible climate change.

The planetary cycle of freshwater includes evaporation, precipitation, continental runoff, atmospheric moisture flux, and, finally, the ocean's own processes of freshwater transport and exchange, ice formation, and melting. These processes determine changes in the storage of freshwater in the global ocean, the main planetary reservoir of this most vital substance. On the flip side, these same processes, along with advection and mixing of salt, control salinity, which is a measure of (or, practically, a proxy for) the concentration of the salts dissolved in seawater. 

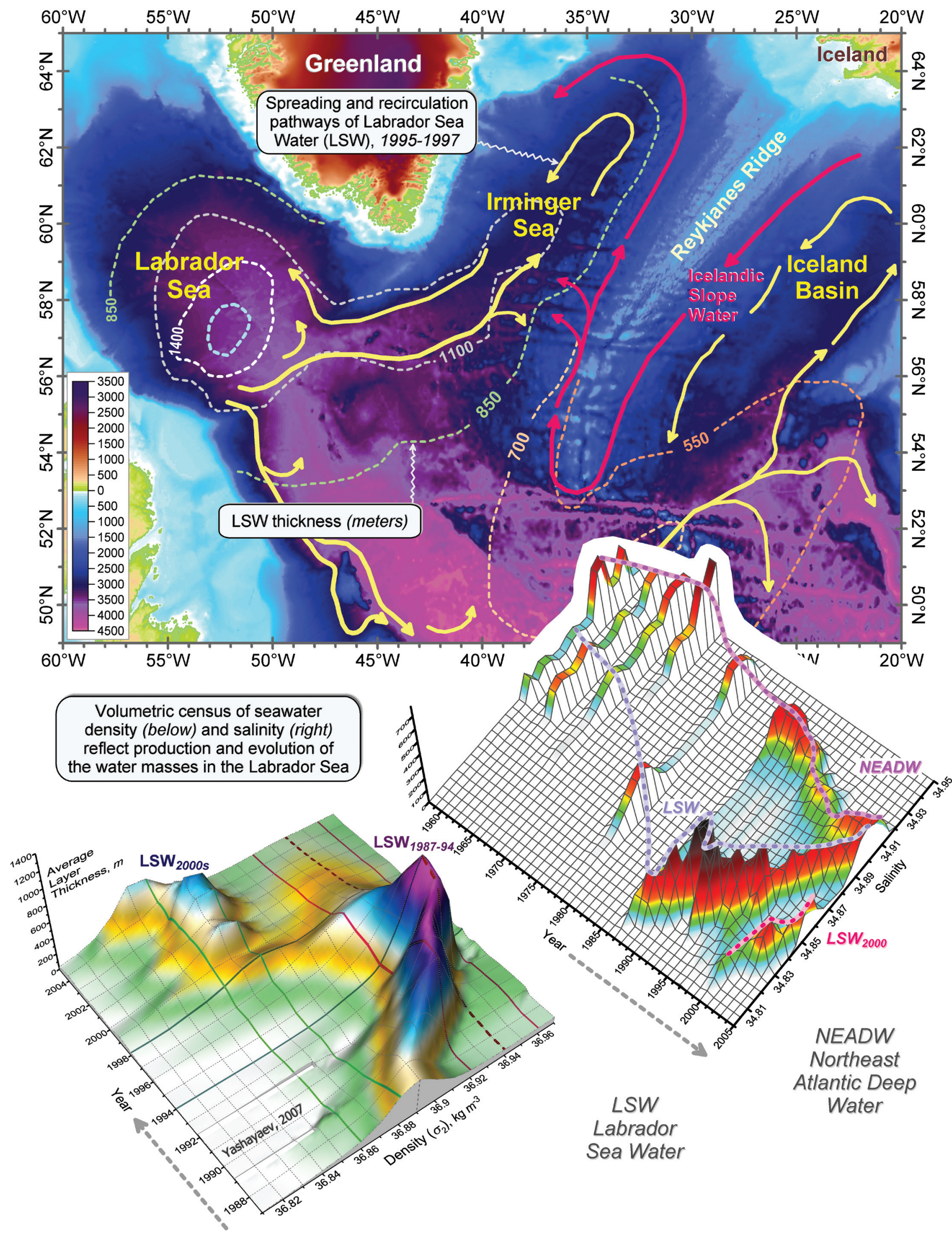
The distribution of temperature and salinity in the subsurface waters of the subpolar gyre of the North Atlantic (Figure 1) results from four processes: 1. The Gulf Stream and then the North Atlantic Current carry warm and salty water from southwest to northeast.

2. The Arctic Ocean outflow delivers the cold, low-salinity water found over the Greenland, Labrador, and Newfoundland shelves.

3. The subpolar gyre's circulation carries the initially warm, salty surface and subsurface waters counterclockwise around the northern and western boundaries of the deep basins. As the water moves westward, it loses heat to the atmosphere and becomes fresher because precipitation exceeds evaporation over these waters.

4. As the upper-layer waters cool, they become denser (heavier), and they mix with the colder, fresher waters found at deeper levels. This process of vertical mixing also contributes to the freshening of the surface and subsurface waters as they move toward the Labrador Sea.

The large-scale pattern of temperature and salinity set by these processes means that each of the three main subpolar basins-the Iceland Basin, the Irminger Sea, and, particularly, the Labrador

Igor Yashayaev (yashayaevi@mar.dfompo.gc.ca) is Research Scientist, Ocean Circulation Section, Ocean Sciences

Division, Bedford Institute of Oceanography, Fisheries and Oceans Canada, Dartmouth, NS, Canada. Allyn Clarke is Scientist Emeritus, Ocean Circulation Section, Ocean Sciences Division, Bedford Institute of Oceanography, Fisheries and Oceans Canada, Dartmouth, NS, Canada.
Sea (Figure 1)—exhibit unique ranges of temperature and salinity that allow their waters to be distinguished from each other. This characterization of waters from their temperatures and salinities is an important tool of classical oceanography that underlies water-mass analysis of any level of complexity. In physical oceanography, a "water mass" denotes a large, relatively homogeneous or uniform body or volume of water, formed in the same source or formation region and by the same process (Dobrovolskiy, 1961). Water masses are defined by their physical (and chemical) properties. In this article, we use seawater salinity as the principal identifier and tracer of major water masses of the subpolar North Atlantic.

In classical oceanography, water masses were thought to be constant in time. Modern, high-precision and repeated measurements show that assumption to be false. Here, we use the spatial and temporal distributions of seawater salinity to illustrate the production and evolution of the intermediate and deep water masses of the subpolar North Atlantic.

\section{UPPER-LAYER CIRCULATION OF THE SUBPOLAR NORTH ATLANTIC}

The subpolar North Atlantic is characterized by an intense, upper-layer circulation (Figure 1) that establishes "communication" lines between the subtropical, subpolar, polar, and coastal regions, thus providing, maintaining, and regulating their exchanges of heat, freshwater, salt, and other substances.
Figure 1 illustrates the Gulf Stream/ North Atlantic Current system, which transports warm, saline water northeastward across the southern boundary of the subpolar gyre. This current is the northern extremity of the upper limb of the ocean conveyor belt. The North Atlantic Current splits into a number of branches and eddies after it crosses the Mid-Atlantic Ridge. The easternmost branch carries some of this warm and salty water through the Faroe-Shetland Channel into the Nordic seas.

Another of these branches passes around the Iceland Basin and then around the Irminger Basin before entering the Labrador Sea. As the waters move westward, winter cooling creates deep, winter-mixed layers whose waters tend to become cooler and fresher along the track (toward the Labrador Sea). These waters are called Subpolar Mode Waters (SPMW) (McCartney and Talley, 1982). In the Irminger and Labrador Seas, the westward branch of the North Atlantic Current is called the Irminger Current. It delivers water originating from the SPMW to the Labrador Sea. This relatively warm, salty water ${ }^{1}$ is an important part of the deep-convection story of the Labrador Sea, as discussed in the next section.

The subpolar gyre also receives cold, low-salinity waters from the Arctic Ocean, as illustrated by blue arrowheaded lines in Figure 1. This circulation is concentrated over the shelves and upper continental slopes and consists of the East and West Greenland and Labrador currents. Most of this Arctic outflow, restricted to the upper layer,

${ }^{1}$ The Irminger Current (containing SPMW) is, in fact, warmer and saltier than the rest of the waters in the Labrador Sea (Figures 3 and 5). 


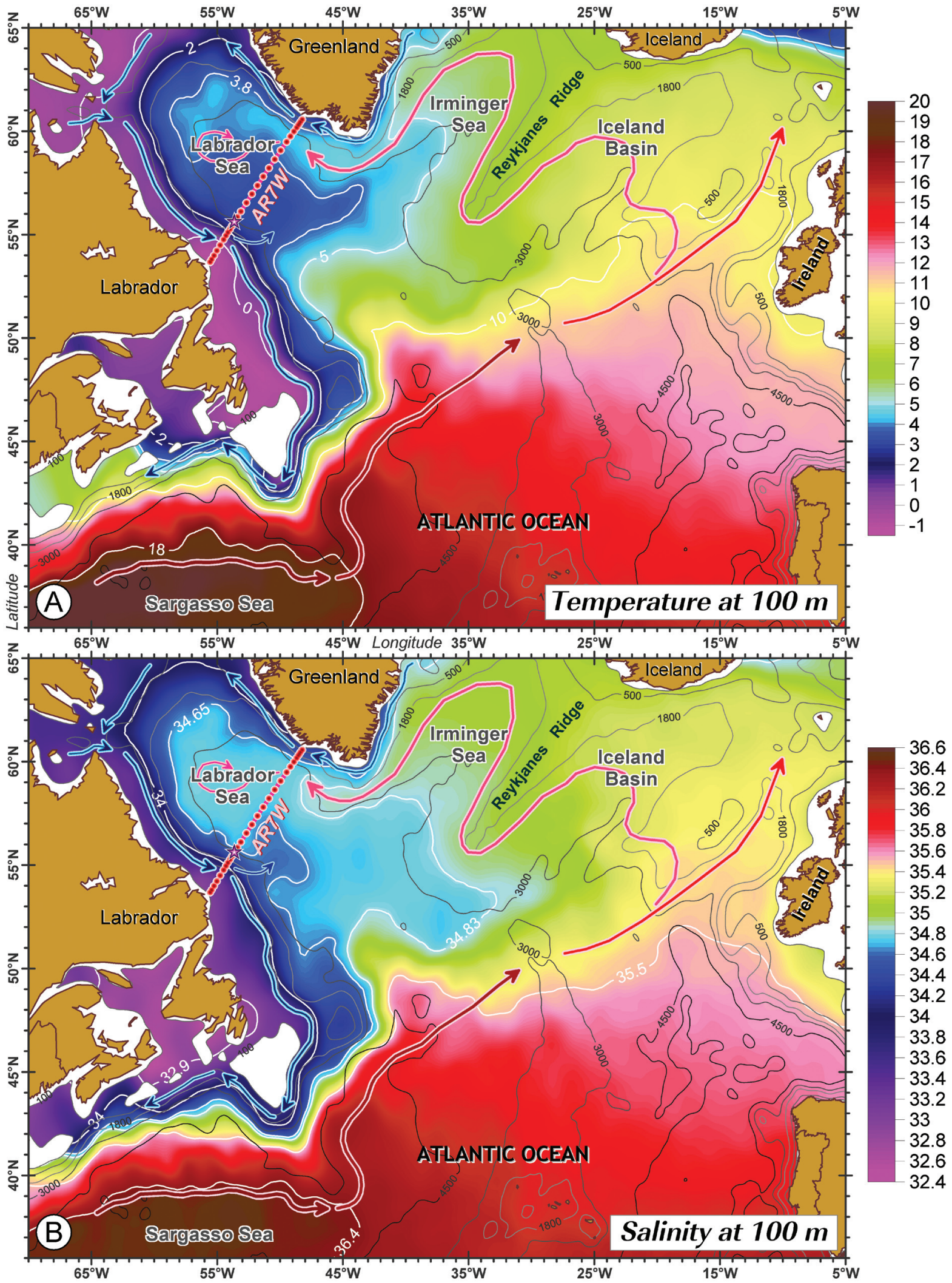

Figure 1. Distributions of temperature (A) and salinity (B) at $100 \mathrm{~m}$ below the surface in the northern North Atlantic. The red arrows indicate the Gulf Stream and associated North Atlantic Current, which transport warm saline surface water. The blue arrows indicate the East and West Greenland and Labrador Currents, which carry relatively cold and fresh water southward. Red circles are the locations of the oceanographic stations on the Labrador Sea repeat hydrography line (AR7W). The star indicates the site that was chosen for Figure 3. 
is the return flow associated with the warm, saline inflow through the FaroeShetland Channel between Iceland and Britain. However, a significant contribution comes from the inflow of water through Bering Strait. The Arctic outflow attains its low salinity in part from this low-salinity North Pacific water and also from the large river runoff into the Arctic Ocean.

\section{INTERMEDIATE AND DEEP} WATER MASSES OF THE SUBPOLAR NORTH ATLANTIC

Because the North Atlantic Current transports warm surface and subsurface water into the subpolar gyre, this region experiences a net annual heat loss to the atmosphere. By the time these waters reach the Labrador Sea to the west or the Greenland Sea and Arctic Ocean to the north, they become dense enough that one more strong winter cooling season will result in deep convectively mixed layers extending to depths of $2 \mathrm{~km}$ and greater.

The warm, saline water transported into the Nordic Seas (Norwegian, Greenland, and Iceland Seas, and Arctic Ocean) is eventually cooled to temperatures close to the freezing point.
Because of their still-high salinity, these cooled waters are the densest waters in the global ocean and form the deep and bottom waters of the Nordic seas. The flow of these dense, deep waters directly into the North Atlantic is restricted by the shallow ridge system joining the Shetlands, the Faroes, Iceland, and Greenland. This dense water flow is confined to three narrow passages: the Faroe Bank Channel, some small gaps to the east of Iceland, and the Denmark Strait between Iceland and Greenland. The sill depths in these gaps are all shallower than $1000 \mathrm{~m}$. The fact that the waters of the Nordic seas are so much denser than those of the northern North Atlantic results in very strong flows through these gaps. These strong currents result in vigorous mixing of the overflow waters with the lighter waters of the North Atlantic as these overflows travel along and down the topography. Figure 2 shows the pathways of the two main overflow-derived water masses, Iceland-Scotland Overflow Water (ISOW) and Denmark Strait Overflow Water (DSOW). These waters are also engaged in a slower "diffusive" spreading process directed towards the centers of the subpolar basins. Changes in their production rates, volumes, and

\section{BOX 1. USEFUL FACTS ABOUT THE EFFECTS OF TEMPERATURE}

AND SALINITY ON SEAWATER DENSITY

Seawater becomes denser as it gets colder and more saline. The impact of temperature on seawater density decreases as the water becomes colder and less saline. At a temperature of $10^{\circ} \mathrm{C}$ and a salinity of 34.85, a $1^{\circ} \mathrm{C}$ temperature change causes more than twice the density change as does a 0.1 salinity change. At $3^{\circ} \mathrm{C}$, the difference is reduced to about $10 \%$. 
mixes with even colder and less-saline East Greenland Current water as it begins its rapid descent along the East Greenland continental slope. During this descent, it passes through and mixes with LSW and ISOW. DSOW is the densest water found in the Irminger Sea, Labrador Sea, and Newfoundland Basins and can be easily identified on vertical sections as a thin layer of relatively cold and fresh water found near the bottom of these basins (Figure 3).

The final water mass that arises in the northern North Atlantic is the LSW. This water is the end product of the westernmost branch of the North Atlantic Current that transports warm, saline water in a cyclonic (counterclockwise) circulation around the Irminger Basin and then into the Labrador Sea south of Cape Farewell. By the time this water reaches the Irminger Sea, it has been sufficiently cooled to form winter mixed layers more than 500-m deep. These waters enter the Labrador Sea as a temperature and salinity maximum and circulate cyclonically around the Labrador Basin. Further winter cooling acting on the warm, saline waters imported from the Irminger Sea mixes these Atlantic waters

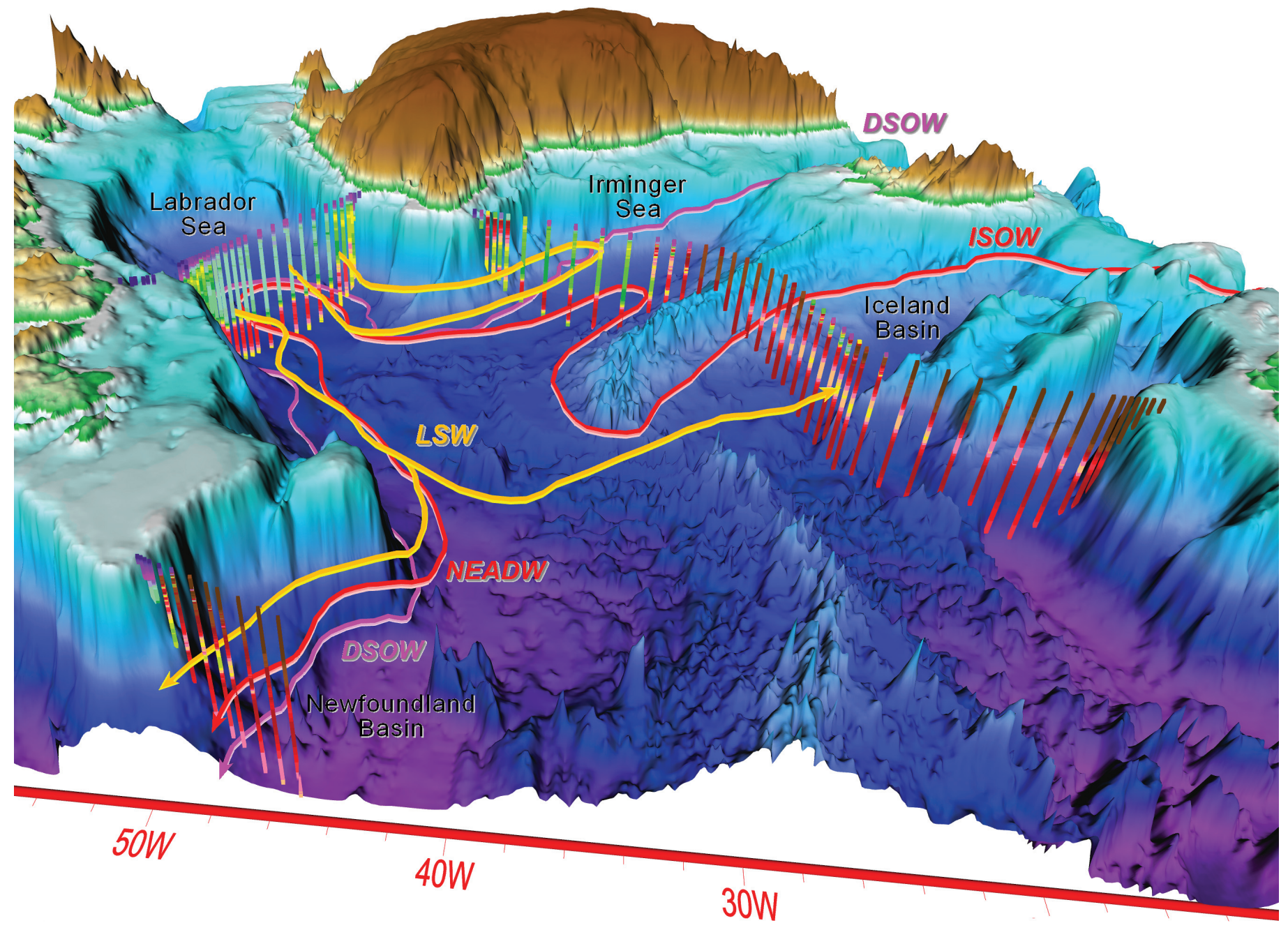

Figure 2. The subpolar North Atlantic and spreading pathways of the three intermediate and deep water masses that form the lower limb of the Atlantic meridional overturning circulation. The 1994 AR7 hydrographic profiles (from Canadian and German oceanographic missions) are vertical lines colored by measured salinity (low-to-high: magenta-blue-green-yellow-red-ruby). LSW indicates the Labrador Sea Water that is produced in the Labrador Sea by deep winter convection. DSOW indicates the deep-basin coldest Denmark Strait Overflow Water. The Iceland-Scotland Overflow Water (ISOW) substantially modifies en route to become Northeast Atlantic Deep Water (NEADW). Note that NEADW is more saline than the other water masses (LSW and DSOW). 


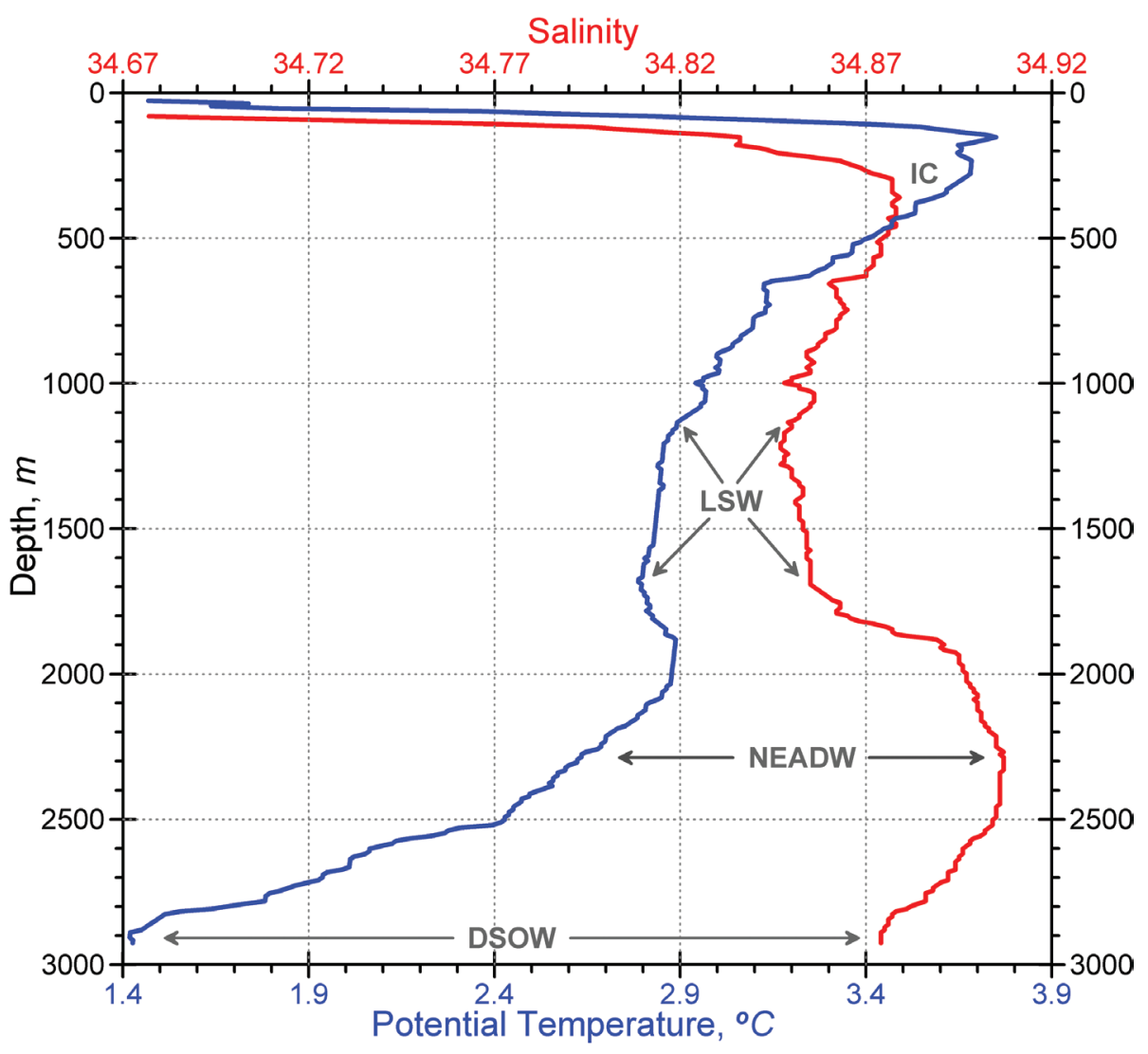

Figure 3. Temperature and salinity profiles for the western Labrador Sea illustrating the different water masses of the subpolar gyre of the North Atlantic (IC indicates the modified Irminger Current water). The measurements used in this diagram were collected in the summer of 1994 (June 3) at about $55.61^{\circ} \mathrm{N}, 53.63^{\circ} \mathrm{W}$ from a water depth of 2925 m (star in Figure 1).

with (1) the cold fresh Arctic outflows arriving from the Denmark and Davis straits along the coasts of Greenland and Labrador ${ }^{2}$, (2) continental runoff, (3) atmospheric precipitation, and, subsequently, (4) the underlying waters. The winter mixed layers created in this process can be more than 2-km deep. These mixed layers are the newly formed LSW. Because the LSW formation process accumulates both the excess of precipitation over evaporation and the relatively fresh Arctic outflows over the subpolar gyre, LSW appears as a broad salinity minimum over the depth range of 1000 to $2000 \mathrm{~m}$ (Figure 3).

As Figure 2 illustrates, LSW circulates around the subpolar gyre of the North Atlantic at depths of 1-2 km. It also escapes the subpolar gyre as part of the deep western boundary current that carries the three North Atlantic deep and intermediate waters southward to the Southern Ocean and hence to the global ocean. This boundary current forms the lower limb of the ocean conveyor belt that, by balancing a warm poleward transport in surface waters with a cold equatorward transport at depth, moves heat from the tropics to higher latitudes.
TEMPERATURE AND SALINITY (THERMOHALINE) CHANGES IN THE LABRADOR SEA

The Labrador Sea has been reasonably well observed over the past five decades, through periods of exceptionally active LSW formation and also periods when there was virtually none. In this section we give a more detailed, though not complete, overview of this water mass, its production, and associated changes.

Three conditions come together to make the Labrador Sea favorable for LSW formation. First, the water entering the Labrador Sea from the Irminger Sea has already been cooled and made denser in its passage around the northern boundary of the North Atlantic. Second, the strong cyclonic circulation in the Labrador Sea causes denser, mid-depth waters to upwell in the interior of the Labrador Sea. These two conditions reduce the density difference between the surface and the LSW layer and make the region more susceptible to deep convection. Finally, cold Arctic outbreaks result in intense atmosphere-ocean heat exchanges over the western Labrador Sea, transferring large amounts of heat from the ocean to the atmosphere. During severe winters, the ocean loses enough heat so that its surface waters become dense enough to convectively mix to intermediate depths (1500-2200 m). LSW formation processes are described in more detail in such papers as Lazier (1980), Clarke and Gascard (1983), Gascard and Clarke (1983), Lazier et al. (2002), Pickart et al. (2002), and Yashayaev (2007b).

Labrador Sea waters have undergone remarkable changes over the past few

${ }^{2}$ Unlike the two dense Arctic overflows that form the deep and bottom water masses of the North Atlantic, the Arctic outflows reside in the upper layer and, because of their low salinities, are not nearly as dense as the overflows. 
decades. The 55-year record (Figure 4) shows three periods when the upper $2000 \mathrm{~m}$ of the Labrador Sea warms and becomes more saline: 1962 to 1971 , 1977 to 1984 , and 1994 to 2005. The first warming period was preceded by a decade in which there was a great deal of interannual variation in water properties. We interpret the sharp deepening of the 36.88 isopycnal (surface of constant density) in $1957 / 58$ and to a lesser degree in 1951/52 as evidence of convective renewal of LSW during those years. Because the surface waters in the Labrador Sea are less saline than the deeper waters, the appearance of deep intrusions of colder, less-saline water is the signature of recent convection.

On two occasions since 1960, the Labrador Sea experienced extended periods of strong winter convection resulting in formation of significant volumes of LSW with distinctive temperature-salinity signatures. The first took place from 1972 through 1976 and eventually renewed LSW to a depth greater than $2000 \mathrm{~m}$ and $\sigma_{2}=36.92$ $\left(\sigma_{2}\right.$ denotes potential density anomaly referenced to 2000 dbar). This "new" LSW was $0.4^{\circ} \mathrm{C}$ cooler and more than 0.05 less saline than the LSW properties over the previous decade. Fortuitously, the final deep convection during the winter of 1975/76 was directly observed (Clarke and Gascard, 1983).

The most remarkable event of convective water-mass renewal occurred between the mid-1980s and mid-1990s. Convective cooling and freshening of the Labrador Sea's mid-depths produced a characteristic LSW that by 1994 became the coldest, densest, deepest, and most

\section{BOX 2. THE ROLE OF THE SUBPOLAR NORTH ATLANTIC IN THE ATLANTIC OVERTURNING CIRCULATION}

Through production of its characteristic intermediate (LSW), deep (ISOW/NEADW), and abyssal (DSOW) water masses, the northern North Atlantic contributes to the meridional overturning circulation (MOC) of the whole Atlantic Ocean. These waters form the lower limb of the great ocean conveyor and subsequently participate in the ventilation of the deep layers of the world ocean. By transporting warm water poleward in the upper layers and cold waters equatorward at depth, this circulation is an important mechanism by which the climate system moves heat from the tropics to higher latitudes. It is also a mechanism to sequester carbon dioxide and other greenhouse gases in the ocean's abyssal waters. Changes in the properties and volumes of these water masses through changes in the processes leading to their formation are likely to be reflected in climate change and variability on the regional if not global scale.

voluminous ${ }^{3}$ in the entire observational record (Lazier et al., 2002; Yashayaev et al., 2003; Yashayaev, 2007a, 2007b). Because of the annual occupations of the World Ocean Circulation Experiment (WOCE) Atlantic repeat sections from 1990 to 1997 (AR7W from Labrador to Greenland and AR7E from Greenland to Europe) plus a number of American and German research cruises, the evolution of this strong convective event was well observed. It was caused by the severity of all of the winters from the late 1980s through 1993/94. Each winter's convection raised the deep isopycnal surfaces and reduced resistance to convection in the succeeding winter by reducing stratification. The first several winters served to mix the freshwater that had accumulated in the surface layers over the upper $2000 \mathrm{~m}$. The increase of salinity after 1991 reflects the entrainment of more saline NEADW layer water as well as a greater influence of inflow from the Irminger Sea.

This intense convection ceased following the winter of 1993/94. Over the next decade, this anomalously cold, low-salinity water mass gradually warmed, gained salinity, and collapsed to a thickness of less than $400 \mathrm{~m}$. Weaker convection did take place after 1995. By the winter of 1999/2000, this convection had formed a fresher, warmer, and lighter class of LSW that reached depths greater than $1000 \mathrm{~m}$.

Since 1994, the upper $2000 \mathrm{~m}$ have warmed considerably. The average temperature and salinity of the upper2000-m layer have already returned to the high levels observed in the late 1960s and are likely to surpass these record high levels in the near future (Yashayaev, 2007b). The warming and increasing salinity are maintained by the increasing influence of warm, saline

\footnotetext{
${ }^{3}$ The LSW volume was determined via the thickness of the corresponding layer (e.g., Yashayaev, 2007b).
} 


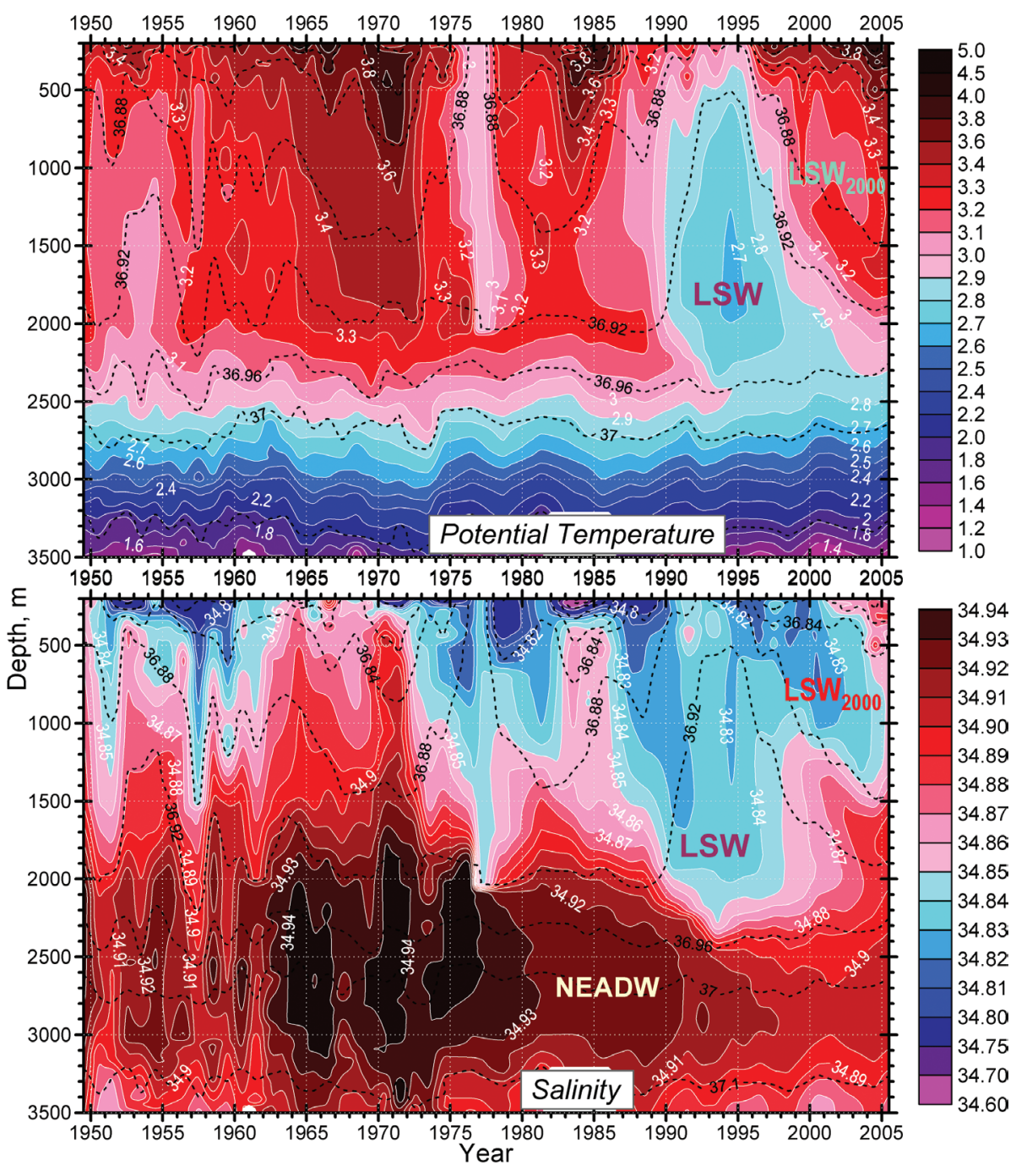

Figure 4. Potential temperature and salinity in the central Labrador Sea (confined by the 3250- $\mathrm{m}$ isobath and the $150-\mathrm{km}$ distance range from the Labrador Sea section AR7W), 1950 to 2007. The 500-2000-m layer is dominated by Labrador Sea Water (LSW). Below this layer, the salinity maximum centered around $2500 \mathrm{~m}$ is the core of the Northeast Atlantic Deep Water (NEADW). The cold, less-saline water at the bottom marks the Denmark Strait Overflow Water (DSOW). All of these layers exhibit strong interannual salinity variability. The intermediate (LSW) and deep (NEADW and DSOW) layers of the Labrador Sea exchange signals with the associated layers of the other North Atlantic basins shown in Figure 2 (Yashayaev et al., 2008; Yashayaev and Dickson, 2008).

This figure was constructed by averaging on density surfaces all of the available temperature and salinity data for each year for the central Labrador Sea. The black dashed contours are the $\sigma_{2}$ (potential density anomaly referenced to $2000 \mathrm{dbars}$ ) isolines (note the changing density of LSW). The data in the upper $200 \mathrm{~m}$ are not displayed because this layer is subject to strong seasonality, which is not adequately resolved by the observations.

Note that up to 1974, most of the data was collected by the US Coast Guard within their Ocean Weather Ship Bravo and Ice Patrol programs. From 1990 on, Bedford Institute of Oceanography has carried out an annual occupation of the AR7W section under the Ocean Climate Monitoring Program of Fisheries and Oceans Canada at the Bedford Institute of Oceanography (Figure 1). These regular sources of data are supplemented by a number of research and fisheries survey cruises conducted by various American, Canadian, Danish, and German groups. There were fewer oceanographic observations in the Labrador Sea during the 1980 s with several years $(1982,1983,1985,1986$, and 1989) having no observations in the central Labrador Sea. These gaps are smoothed over in this figure. waters both in the upper $800 \mathrm{~m}$ and also in the layer separating the remnants of the dense LSW from 1994 and the light LSW formed in 2000. These waters both enter the Labrador Sea from the adjacent Irminger Sea.

Figure 4 also shows salinity changes in NEADW and DSOW. These deep waters were saltiest (and warmest) from 1964 through 1975. Since the 1970s, they have been getting fresher and colder. Some of this freshening and cooling arises through the entrainment of LSW as these water masses first enter the North Atlantic and rapidly descend from their sill depth (Dickson et al., 2002). The rest arises through the cooling and freshening of waters elsewhere in the subpolar gyre as well as in the Nordic Seas.

Convective processes in the Labrador Sea are important mechanisms for the redistribution of freshwater in the North Atlantic. Excess freshwater is delivered to the surface layers through precipitation and via the Arctic outflows within the East Greenland and Labrador currents. Through convection, advection, and mixing, this freshwater is distributed throughout the intermediate and deep waters of the North Atlantic and eventually to the global ocean. Other substances, such as greenhouse gases and airborne pollutants, are similarly redistributed away from the surface layers.

The amount of heat that is lost to the atmosphere (or wintertime cooling) and the character of underlying stratification just before convection (or preconditioning) largely determine the strength of winter convection. Meteorologists and oceanographers have long used the winter North Atlantic Oscillation (NAO) index as a measure of atmosphericcirculation strength over the northern 
North Atlantic (Hurrell et al., 2001). The NAO index is the normalized Azoresto-Iceland sea-level pressure difference, which is linked to the strength of the westerly winds over the central North Atlantic. Although an NAO index can be computed throughout the year, it is only the winter pattern that has a dominant impact on the weather and ocean conditions in northeastern North America and Europe.

High positive NAO index values are associated with a deep, low-pressure area over Iceland and winter storms tracking from the Newfoundland Grand Banks up across Iceland into the Nordic seas. In the Labrador Sea, this pattern results in cold, strong northwesterly winds, broad ice packs over the Labrador and northern Newfoundland shelves, and intense ocean heat losses, particularly on the western side of the basin. The winter NAO index exhibits a great deal of interannual variability. The 1972-1976 and 1988-1994 periods of cooling and freshening of the Labrador Sea associated with renewal of the intermediate waters to $2000 \mathrm{~m}$ and deeper correspond to the well-defined periods of sustained, high positive values of the NAO index (Yashayaev, 2007b). In contrast, a predominance of negative NAO years from 1962 through 1971 coincides with the period of little LSW convective renewal when it was becoming warmer and more saline (see also the 1966 section in Figure 5a and Lazier, 1980).

The relationship between the NAO index and LSW production and properties evident on decadal time scales is not that straightforward from one year to next, because significant local processes force the ocean on interannual scales (Yashayaev, 2007b). For example, the water column establishes considerable stability during a sustained period without convection. It takes several consecutive cold winters to overcome this stability and to renew the densest LSW classes. Alternatively, a moderately cold winter following a series of particularly intense winters can still drive deep convection because the water column enters the cooling season with little stability to overcome. In addition, the NAO index is a large-scale regional climate index. The local wind field over the Labrador Sea is not always directly related to the strength of the westerlies over the central North Atlantic (Yashayaev, 2007b).

\section{THE TRANS-ATLANTIC SIGNATURE OF LABRADOR SEA WATER}

LSW spreads across the subpolar North Atlantic as an intermediate water mass that is relatively fresh, cold, and rich in dissolved gases. LSW can be distinguished in hydrographic profiles as an intermediate-depth salinity minimum.

Figure 5 displays the salinity distribution across the subpolar gyre in four different years over the past four decades. The Labrador Sea experienced a few winters of moderate convection preceding 1962 (Figure 5a). The LSW appears in the Labrador Basin as a thick layer with salinity less than 34.88 . It also appears as an equally thick water mass whose salinity is less than 34.90 in the Irminger Basin to the east of Greenland. Further east, LSW continues to appear as a salinity minimum, though of less thickness and greater salinity. This decrease in thickness and increase in salinity is present in each of the four years displayed in Figure 5. This pattern is consistent with the hypothesis that LSW is formed in the
Labrador Basin by winter convection and then is carried eastward into the other basins by the interior circulation within the subpolar gyre (Lavender et al., 2005). It is probably not strictly correct to speak of forming LSW within the Labrador Basin. The process is better thought of as a transformation or renewal of LSW. Deep convection does not occur every year in the Labrador Sea, but when it does, much or a significant part of the volume of water that becomes the new class of LSW is a transformed older class of LSW. Convection simply resets the renewed LSW properties and creates a more homogeneous layer through vertical mixing. The new LSW spreads to all of the other subpolar basins, and is transformed by isopycnal mixing en route (Yashayaev et al., 2007a, 2007b). As the LSW circulates around the subpolar gyre, its salinity increases because it is always mixing with greater-salinity waters, but it retains more or less the same density because its mixing is largely isopycnal (Yashayaev et al., 2007b).

Figures $5 b$ and $5 c$ highlight the two extreme states in the observational history of LSW: the warm, saline 1960s with little convective renewal and the cold, fresh mid-1990s with prolonged deep convection. The LSW seen in the Labrador and Irminger Basins in the 1962 section (Figure 5a) was likely produced during the cold winter of 1960/61. Our observations indicate that there was no significant renewal of LSW until the intense winter of 1972. In the 1966 section (Figure 5b), LSW appears in the Labrador Sea as a 500-m-thick layer of water with salinities between 34.88 and 34.9 and as weak salinity minima in the eastern basins. The intermediate layer of the Labrador Sea continued to become 

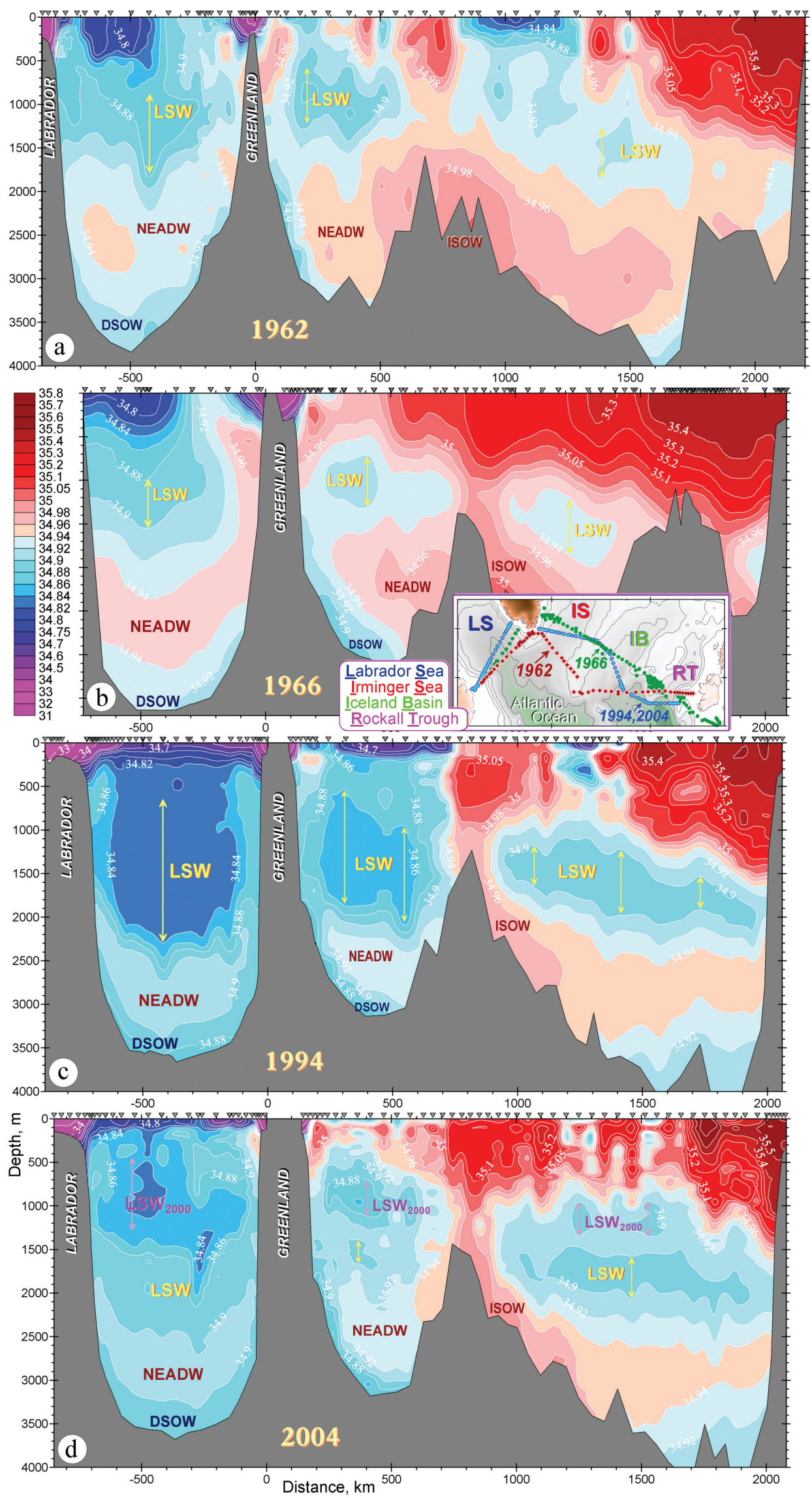

Figure 5. Trans-Atlantic salinity sections from 1962 (a), 1966 (b), 1994 (c), and 2004 (d). Sampling/profiling sites are shown in inserts. The earlier two sections arose from research cruises in the 1960s, the 1962 Erika Dan cruise out of Woods Hole Oceanographic Institution (Worthington and Wright, 1970), and the 1966 Hudson cruise out of Bedford Institute of Oceanography (Grant, 1968). The two later sections are taken from the western (AR7W) and eastern (AR7E) parts of the World Ocean Circulation Experiment (WOCE) repeat section AR7, which currently serves as the key outpost of the Climate Variability and Predictability (CLIVAR) program in the subpolar North Atlantic. LSW appears as a prominent feature on each of these sections although with varying strengths and properties. 
warmer and saltier until deep convection was reestablished in 1972.

The 1994 section (Figure 5c) followed a period during which six of the preceding winters had high positive NAO indices and resulted in strong winter convection. This recent convection and the earlier periods of convection in the 1970 s and early 1980s resulted in the freshening of the LSW across the entire section as compared to the earlier sections from the 1960s. The LSW has not only freshened, but its layer thickness has more than tripled in the Labrador Basin and doubled in the Irminger Basin and in the eastern North Atlantic.

The 150-2000-m mean temperature and salinity in the central Labrador Sea decreased $1^{\circ} \mathrm{C}$ and 0.08 , respectively, between 1970 and 1994. These changes resulted in a decrease in sea level of more than $10 \mathrm{~cm}$. This contraction of the water column is due to its cooling, which makes the water denser. The accompanying freshening opposes the cooling effect by decreasing the density and leading to an expansion of the water column. The impact of the cooling is twice that of the freshening; consequently, the temperature largely determines the water density.

The 1970 to 1994 period shows a significant accumulation of freshwater throughout the entire subpolar gyre. For the central Labrador Sea, in particular, the 1970 to 1994 change in salinity represents an accumulation of at least $6 \mathrm{~m}$ of freshwater. The Irminger Sea has experienced a similar freshening, while the freshening in the eastern basins is of lesser extent and strength. The freshening is not confined to the LSW; it extends to the deeper layers-ISOW, NEADW, and DSOW-and to the shallower waters of the Irminger and Labrador
Seas (e.g., IC). These two extreme LSW states are reflected in markedly different vertical stratification and overall water-mass distribution throughout the whole subpolar domain.

The two mild winters of 1994/95 and $1995 / 96$ resulted in the strong LSW water mass seen in 1994 becoming thinner as its waters are carried out of the Labrador and Irminger seas. As the layer thins, less-dense water flows in above it, reestablishing stratification between the LSW and the surface layer. More severe winters then returned, with a particularly strong cooling in 1999/2000. Convection during this winter formed a lighter LSW version that can still be seen in the 2004 section as a layer filling the 500-1500-m depth range in the Labrador Sea (Figure 5d). By 2004, this water mass spread to the Irminger Basin and the eastern North Atlantic. The denser LSW class from 1994 is also visible in all the basins in the $2004 \mathrm{sec}$ tion. It is particularly interesting that this older LSW class retained such a strong signature within the eastern North Atlantic a decade and $2000 \mathrm{~km}$ from its formation event in the Labrador Sea.

From the fragments of the 1962 Erika Dan sections (Worthington and Wright, 1970), we were able to construct a composite section (Figure 5a) whose regional coverage is similar to those of the other trans-Atlantic sections discussed (Figure 5b-d). The 1962 section indicates that the North Atlantic was generally fresher and colder in that year than in 1966, with the traces of several LSW classes spreading across the subpolar North Atlantic (similar to 2004). Some of these waters are likely to represent remnants of the colder and fresher LSW produced in the 1950s (Yashayaev et al., 2003). It appears that 1962 had the same relation to the 1950 s as the recent years (e.g., 2004) had to the early-tomid-1990s (Figures 4 and 5). Similar to the recent observations, in 1962 we observe fragments of the warm and saline Icelandic Slope Water (Yashayaev et al., 2007a, 2007b) separating fresher and colder LSW classes.

\section{SPATIAL AND TEMPORAL WATER MASS TRANSFORM- ATIONS IN THE SUBPOLAR NORTH ATLANTIC}

Potential temperature $(\theta)$ - salinity (S) analysis presents another insightful instrument for understanding the evolution of water masses. In the following section, we use the volumetric $\theta-S$ method to measure the changes in water-mass volumes and properties within the subpolar gyre of the North Atlantic. The diagram is constructed by computing the thickness of each $\Delta \theta \times \Delta S$ layer and then computing a weighted average of that thickness for the oceanic region in question.

Figure 6a shows the changes in watermass structure and properties over the entire Labrador Sea AR7W section from 1994 to 2004. In 1994, the water column is dominated by the strong class of LSW created through a series of intense winters from 1987 through 1994. By 2000 , the average thickness of this layer has decreased to about a quarter of its original value. Its salinity has increased by about 0.04 , and it has also warmed by $0.2^{\circ} \mathrm{C}$, resulting in the peak shifting to a slightly higher density. The peak is still easily identified as a salinity minimum and also a maximum in mean layer thickness. By 2004, the waters in this density range have increased their salin- 
a
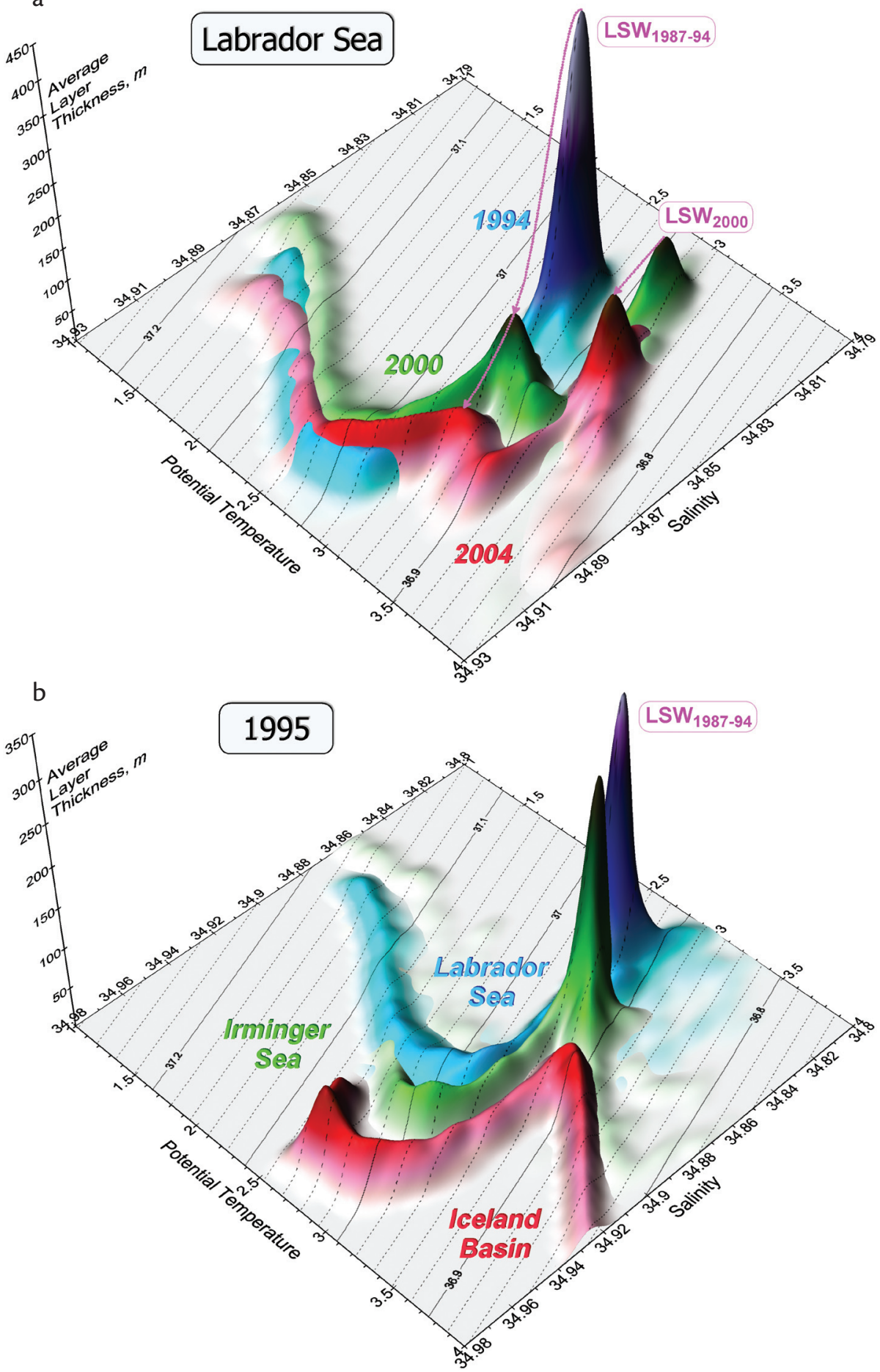

Figure 6. "Volumetric" potential temperature $(\theta)$ - salinity (S) censuses of the Labrador Sea in 1994, 2000, and 2004 (a), and the Labrador, Irminger, and Iceland basins in 1995 (b). Each of the volumetric diagrams was based on the average vertical thicknesses (in meters) of $\theta$-S layers defined by $\Delta \theta$ and $\Delta S$ intervals of $0.1^{\circ} \mathrm{C}$ and 0.01 , respectively. The solid and dashed contours are isolines of $\sigma_{2}$ (in $\mathrm{kg} \mathrm{m}^{-3}$ ); $\sigma_{2}$ is potential density anomaly referenced to $2000 \mathrm{dbar}$ and defined as a function of $\theta$ and $\mathrm{S}$. ity by another 0.02 . The LSW class is still identifiable as a salinity minimum; however, it no longer appears as a maximum in layer thickness. This result means that the salinity signature of the 1994 LSW class still circulates within the subpolar gyre as a passive tracer, but this water mass no longer has an impact on that circulation as it did in the years when it was abundant (e.g., Boessenkool et al., 2007, connect the changes in the ISOW strength with variations in LSW).

Figure $6 \mathrm{~b}$ shows the water masses of the Labrador, Irminger, and Iceland basins as observed along both the east and west segments of the WOCE Atlantic repeat sections during 1995. The strong LSW peak in layer thickness appears in both the Labrador and Irminger seas with the Irminger peak being slightly less and about 0.02 more saline. We hypothesize that this increase in salinity arose through mixing as this LSW volume advected from the Labrador Sea to the Irminger Sea. There is no layer thickness peak in the Iceland Basin and the salinity minimum identifies LSW, which is considerably warmer, more saline, and less dense than that observed in the western basins. This observation indicates that the LSW from the 1987-1994 convective events has not yet fully arrived in the Iceland Basin. What we are seeing in this basin are the remains of the weaker convection events of the earlier periods.

A second layer-thickness peak appears in the 2000 survey of the Labrador Sea (Figure 6a). This layer is a less-dense LSW variant, which replaced its denser and deeper predecessor in the upper $1500-\mathrm{m}$ layer. The thickness of this peak increases slightly from 2000 to 2004 and its temperature and salinity also 
increased. This thickness increase would suggest that convective renewal of this water mass occurred during some of the winters following 2000. The new LSW class can also be identified in the 2004 section plot (Figure $5 d$ ). It took about four years (from 2000 to 2004) for this water to reach the Iceland Basin (salinity minima between 700 and $1300 \mathrm{~m}$ ).

The deep waters below the LSW also change their properties in time and space. The salinity maximum in the potential temperature range of $2-3^{\circ} \mathrm{C}$ (representing NEADW) freshens by 0.02 between 1994 and $2000^{4}$ and then regains more than a half of that freshening by 2004 (Figure 6a). This pattern is consistent with the hypothesis that the freshening was largely caused by the entrainment of the anomalously fresh class of LSW as the NEADW passed through the Iceland Basin. The NEADW is most saline in the Iceland Basin, fresher in the Irminger Basin, and freshest in the Labrador Sea (Figure 6b). The NEADW core occupies a slightly higherdensity range in the Iceland Basin than west of the Mid-Atlantic Ridge-another sign that the freshening of NEADW along its path from east to west is the result of entrainment of the lighter LSW.

The coldest water on this Iceland basin section is about $2.3^{\circ} \mathrm{C}$. At these temperatures, the NEADW is distributed between two peaks. The saltier NEADW is trapped along the eastern flank of the Reykjanes Ridge. This water is the newer NEADW flowing around the boundary of the basin from its entry through the Faeroe Bank Channel. It will eventually enter the Irminger Basin through the Charlie Gibbs Fracture Zone. The fresher peak is found beneath the deep salinity maximum in the interior of the Iceland Basin.

The NEADW is the densest water in the eastern basin. In the Irminger and Labrador basins, the waters denser than this deep salinity maximum are the product of mixing between NEADW and DSOW. These waters are considerably fresher (0.01-0.02) in the Irminger Basin (Figure 6b) than in the Labrador Basin, and they extend to colder temperatures and greater densities. The DSOW enters the Irminger Sea as cold, fresh, dense water and continues to mix with warmer, saltier water as it moves along the western boundary of the Irminger Sea and around the Labrador Sea. Although the western Irminger Sea layer thicknesses on a section plot are a similar magnitude to those observed along the boundaries of the Labrador Sea (Figure 5), this water only appears in some of the Irminger Sea stations. Thus, the volumetric analysis (Figure 6b) shows a much stronger signature in the Labrador Sea than in the Irminger.

Figure 6 captures the time and space changes of the various water masses of the North Atlantic across a single trans-Atlantic oceanographic section. Figure 7 provides volumetric analyses for the western subpolar gyre for the two extreme periods of the last six decades - the warm, salty period of the late 1960s and the cold, fresh period of the mid 1990s. Fortunately, the extensive regional surveys conducted during both periods provide good three-dimensional maps of the water masses of these periods. Figure 7 captures the extensive freshening of the deep subpolar basins from the 1970s to the 1990s. Dickson et al. (2002) document this freshening. It is important to emphasize that this figure illustrates the differences between the two extreme states of these water masses. The warm, saline conditions seen at the end of the 1960s were the result of several years of cumulative warming and increasing salinity (Yashayaev, 2007b). The last decade has seen a similar salinity increase (Figure 4) accompanied by a warming of the water column.

Figure 7 shows that not only have the properties of the water masses changed between these two states, but their relative volumes have also changed. The most noticeable change in volumetric projections is LSW. This water was not just colder, fresher, and denser in the 1990s than before, but it also significantly expanded in volume. For the most part, the LSW volume increased at the expense of the deeper waters, with the LSW taking over a part of both the depth and density range previously occupied by NEADW. Both the NEADW and the DSOW became less saline in the later period.

The volumetric method also provides estimates of the volume of freshwater accumulated in each layer during this freshening event. According to Yashayaev (2007b), the 1960s-to-1990s accumulation of freshwater in the LSW reservoir is equivalent to mixing of an approximately 2.5-m layer of freshwater into it, while the waters between the LSW layer and the 200-m layer gained the equivalent of an additional 0.4-m layer of freshwater. The analogous estimates for the NEADW and DSOW reservoirs are $0.6 \mathrm{~m}$ and $0.3 \mathrm{~m}$, respectively.

${ }^{4}$ The NEADW freshening fully stopped in the Labrador Basin only in 2001 (Yashayaev et al., 2007b); however, the last annual salinity decrease (<0.005 between 2000 and 2001) was smaller than those of previous years. 


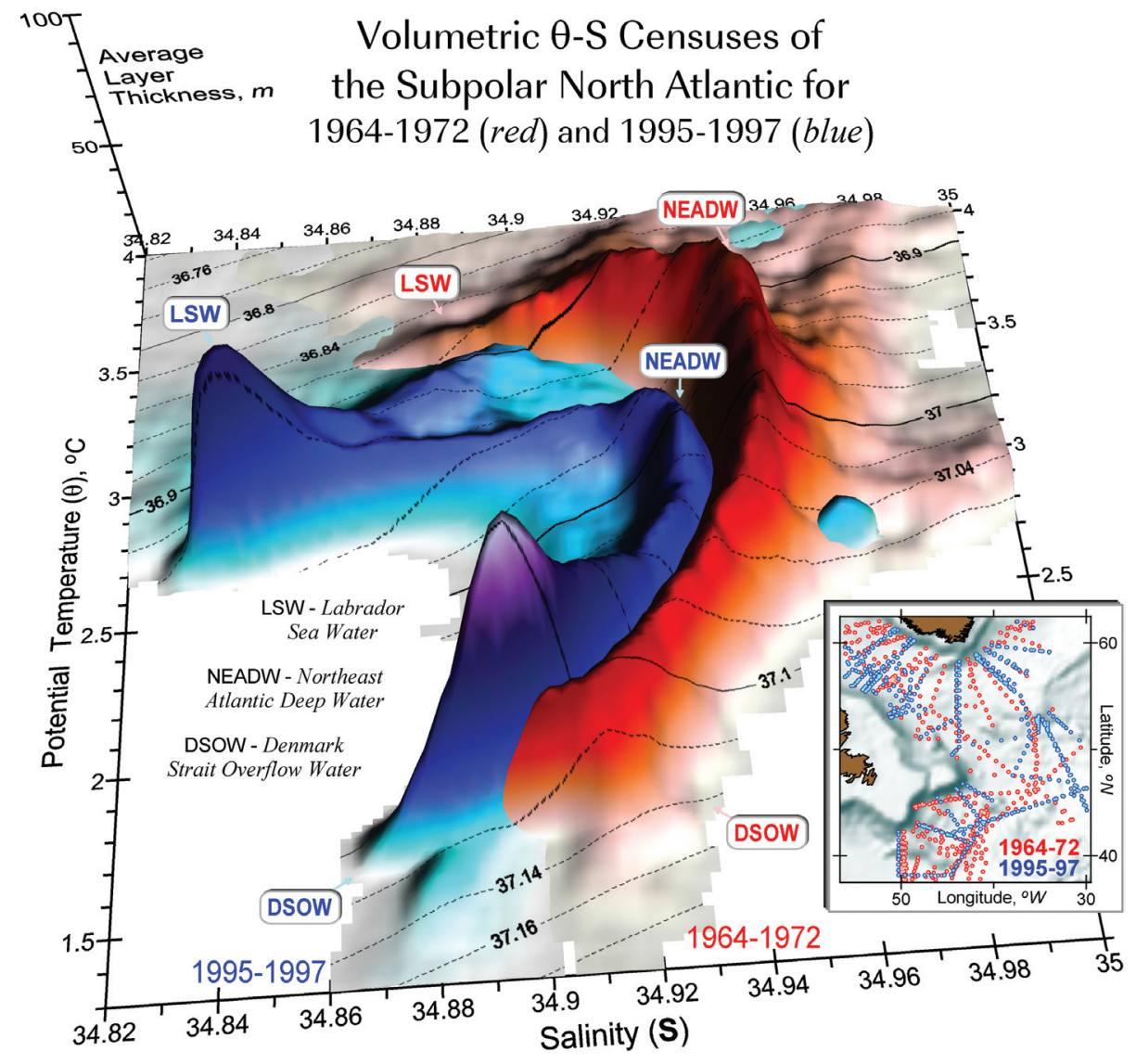

Figure 7. "Volumetric" potential temperature - salinity $(\theta-S)$ censuses of the western subpolar North Atlantic for 1964-1972 (red) and 1995-1997 (blue), from Yashayaev, 2007b. The surface heights reflect average thickness (in meters) of the corresponding $0.1^{\circ} \mathrm{C} \times 0.01 \Delta \theta \times \Delta \mathrm{S}$ layers. The inset map shows the locations of full-water-depth $\theta$-S profiles used in the hydrographic compilations for the 1960 s and the 1990s.

The average water column of the western subpolar gyre of the North Atlantic gained, in total, about $3.9 \mathrm{~m}$ of freshwater over this $(\sim 25$-year $)$ time period.

\section{IMPACTS OF TEMPERATURE} AND SALINITY CHANGES

IN THE LABRADOR SEA ON NORTH ATLANTIC OCEAN WATER-MASS COMPOSITION AND CIRCULATION

Winter convection in the Labrador Sea is a principal mechanism by which the intermediate and deep waters of the North Atlantic are ventilated. This venti- the Rockall Trough in the eastern North Atlantic. These anomalies also move equatorward within the western boundary current and can be observed down to the tropics (Talley and McCartney, 1982; Yashayaev, 2000).

Changes in the strength of winter convection do not just alter the physical properties of the water masses, they also affect the water masses' relative layer thicknesses and volumes, and thus lead to changes in sea-surface height in the interior of the basins. The sea-surfaceheight changes regulate the strength of the subpolar gyre and also lead to changes in the dynamic height gradient between the subpolar gyre and the subtropical gyre, possibly influencing the volume transport of the North Atlantic Current (Curry and McCartney, 2001). A weak gradient acts to contract the subpolar gyre as well as reduce the transport, pulling the subpolar front eastward and drawing more subtropical water into the eastern subpolar gyre (Hakkinen and Rhines, 2004; Hátún et al., 2005).

LSW contributes greatly to the formation of the water masses that eventually fill the deep basins of the northern North Atlantic and form the lower limb of the MOC. As ISOW and DSOW descend from their shallow sills in the narrow passages through the Greenland-IcelandFaroe-Shetland-Scotland ridges, they mix briefly with surface mode waters, and, in a more prolonged way, mix with the intermediate LSW (Dickson et al., 2002) and increase their volumes by factors of four to six. If there has been strong convection in the Labrador Sea, then much of this entrained water has been in recent contact with the surface. In this case, this mixing process is an effective mechanism to carry substances 
such as carbon dioxide from the atmosphere into the abyssal ocean. If convection is weak, then this entrained water has circulated around the gyre for several years or more without atmospheric contact, thus slowing the transfer of material into the deep ocean.

The thickness of the LSW layer near the overflow sites is also thought to influence the strength of the overflows themselves. Boessenkool et al. (2007) attributed changes in the strength of the inflow of ISOW to changes in the volume of LSW. Understanding the processes that govern the strength of the MOC's lower limb remains a challenge to both oceanographers and ocean and climate modelers. The hydrographic observations of the last six decades suggest that conducting a regular oceanographic section across the Labrador, Irminger, and eastern basins is an effective way of observing the variability of these systems. Our group in the Ocean Sciences Division of the Bedford Institute of Oceanography hopes to maintain the annual spring Labrador Sea occupation indefinitely. It remains to be seen whether the next few winters will develop warmer and saltier conditions than those of the late 1960s or initiate a new cycle of LSW renewal and freshening.

\section{ACKNOWLEDGEMENTS}

The authors thank the anonymous reviewer for very valuable comments and suggestions, and we also thank the many colleagues who over several decades have surveyed the subpolar North Atlantic, supported observing programs, and most generously helped in our research. Fisheries and Oceans Canada (DFO) at the Bedford Institute of Oceanography is gratefully acknowledged for its ongoing support of oceanographic surveys of the Labrador Sea under its Ocean Climate Monitoring program. [ed

\section{REFERENCES}

Boessenkool, K.P., I.R. Hall, H. Elderfield, and I. Yashayaev. 2007. North Atlantic climate and deep-ocean flow speed changes during the last 230 years. Geophysical Research Letters 34(L13614), doi:10.1029/2007GL030285.

Clarke, R.A., and J.-C. Gascard. 1983. The formation of Labrador Sea Water. Part I: Large-scale processes. Journal of Physical Oceanography 13(10):1,764-1,778.

Curry, R.G., and M.S. McCartney. 2001. Ocean gyre circulation changes associated with the North Atlantic Oscillation. Journal of Physical Oceanography 31:3,374-3,400.

Dickson, R.R., I. Yashayaev, J. Meincke, B. Turrell, S. Dye, and J. Holfort. 2002. Rapid freshening of the deep North Atlantic Ocean over the past four decades. Nature 416:832-837.

Dobrovolskiy, A.D. 1961. On the definition of "water masses" (Ob opredelenii vodnikh mass). Oceanology (Oceanologia) 1:5-12.

Gascard, J.-C., and R.A. Clarke. 1983. The formation of Labrador Sea water. Part II: Mesoscale and smallerscale processes. Journal of Physical Oceanography 13(10):1,780-1,797.

Grant, A.B. 1968. Atlas of Oceanographic Sections: Temperature-salinity-dissolved oxygen-silica, Davis Strait-Labrador Basin-Denmark StraitNewfoundland Basin, 1965-1967. Atlantic Oceanographic Laboratory, Rep AOL 68-5, Bedford Institute of Oceanography, Dartmouth, NS, Canada, 80 pages.

Hakkinen, S., and P.B. Rhines. 2004. Decline of subpolar North Atlantic circulation during the 1990s. Science 304:555-559.

Hátún, H., A.B. Sando, H. Drange, B. Hansen, and H. Valdimarsson. 2005. Influence of the Atlantic subpolar gyre on the thermohaline circulation. Science 309:1,841-1,844.

Hurrell, J.W., Y. Kushnir, and M. Visbeck. 2001. The North Atlantic Oscillation. Science 291(5504):603-605.

Lavender, K.L., W.B. Owens, and R.E. Davis. 2005. The mid-depth circulation of the subpolar North Atlantic Ocean as measured by subsurface floats. Deep-Sea Research Part I 52:767-785.

Lazier, J.R.N. 1980. Oceanographic conditions at OWS Bravo 1964-1974. Atmosphere-Ocean 18(3):227-238.

Lazier, J.R.N., R.M. Hendry, R.A. Clarke, I. Yashayaev, and P. Rhines. 2002. Convection and restratification in the Labrador Sea, 1990-2000. Deep-Sea Research Part I 49(10):1,819-1,835.

McCartney, M.S., and L.D. Talley. 1982. The subpolar mode water of the North Atlantic Ocean. Journal of Physical Oceanography 12(11):1,169-1,188.

Pickart, R.S., D.J. Torres, and R.A. Clarke. 2002. Hydrography of the Labrador Sea during active convection. Journal of Physical Oceanography 32(2):428-457.

Talley, L.D., and M.S. McCartney.1982. Distribution and circulation of Labrador Sea Water. Journal of Physical Oceanography 12(11):1,189-1,205.

Worthington, L.V., and W.R. Wright. 1970. North Atlantic ocean atlas of potential temperature and salinity in the deep water including temperature, salinity and oxygen profiles from the Erika Dan Cruise of 1962. Woods Hole Oceanographic Institution Atlas Series, 2, 24 pp and 58 plates.

Yashayaev, I. 2000. 12-year hydrographic survey of the Newfoundland Basin: Seasonal cycle and interannual variability of water masses. ICES (International Council for the Exploration of the Sea), CM 2000, L-17, 19 pp. Available online at: http://www.ices.dk/products/CMdocs/2000/L/ L1700.pdf (accessed February 4, 2008).

Yashayaev, I. 2007a. Changing freshwater content: Insights from the subpolar North Atlantic and new oceanographic challenges. Progress in Oceanography 73(3-4): 203-209, doi: 10.1016/j.pocean.2007.04.014.

Yashayaev, I. 2007b. Hydrographic changes in the Labrador Sea, 1960-2005, Progress in Oceanography 73(3-4):242-276, doi 10.1016/ j.pocean.2007.04.015.

Yashayaev, I., J.R.N. Lazier, and R.A. Clarke. 2003. Temperature and salinity in the central Labrador Sea. ICES Marine Symposia Series 219:32-39.

Yashayaev, I., M. Bersch, and H.M. van Aken. 2007a. Spreading of the Labrador Sea Water to the Irminger and Iceland basins. Geophysical Research Letters 34(L10602), doi:10.1029/2006GL028999.

Yashayaev, I., H.M. van Aken, N.P. Holliday, and M. Bersch. 2007b. Transformation of the Labrador Sea Water in the Subpolar North Atlantic. Geophysical Research Letters 34(L22605), doi:10.1029/ 2007 GL031812.

Yashayaev, I., and R.R. Dickson. 2008. Transformation and fate of overflows in the northern North Atlantic. Chapter 21 in Arctic-Subarctic Ocean Fluxes: Defining the Role of the Northern Seas in Climate. R.R. Dickson, J. Meincke, and P. Rhines, eds. Springer.

Yashayaev, I., N. P. Holliday, M. Bersch, and H. M. van Aken. 2008. The history of the Labrador Sea Water: Production, spreading, transformation and loss. Chapter 24 in Arctic-Subarctic Ocean Fluxes: Defining the Role of the Northern Seas in Climate. R.R. Dickson, J. Meincke, P. Rhines, eds, Springer. 